\title{
edificios de viviendas
}

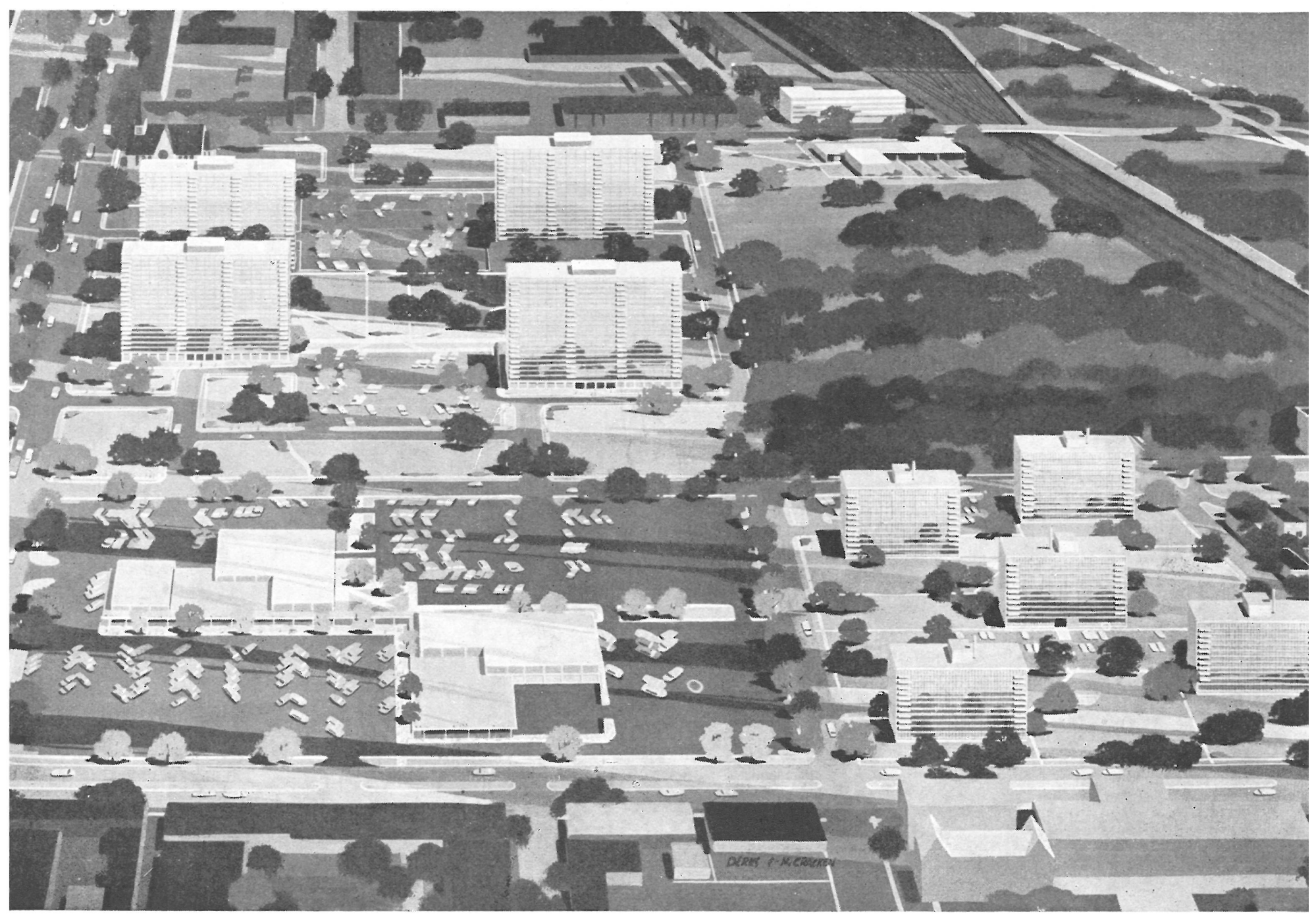

$123 \cdot 49$

\section{LAKE MEADOWS Chicago}

SKIDMORE, OWINGS y MERRILL, arquitectos 


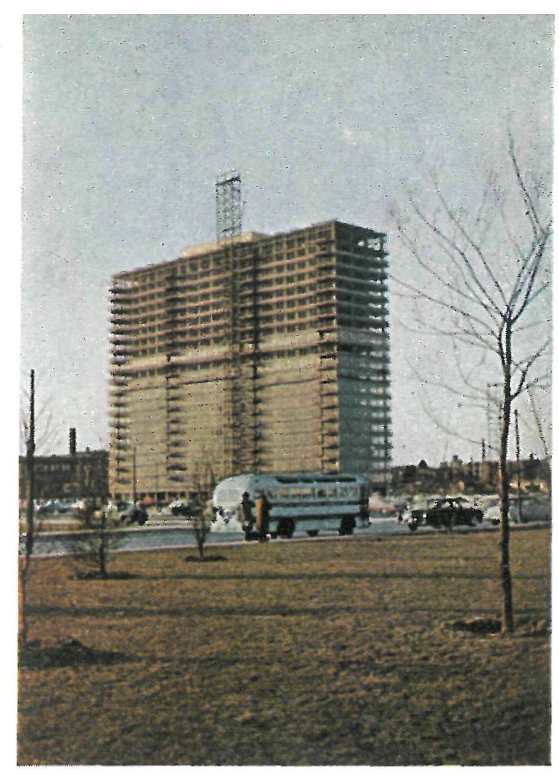

"Lake Meadows" es una amplia parcela, de cuatrocientos mil metros cuadrados, situada en las afueras de Chicago, con vistas dominantes sobre el lago Michigán. En tan bello emplazamiento

se ha construído uno de los más atractivos conjuntos residenciales norteamericanos.

Adoptada la solución de bloques en altura, solución rara vez empleada en viviendas en Estados Unidos, la superficie edificada ocupa sólo el $9 \%$; el $91 \%$ restante lo constituyen jardines, parques de recreo infantil, accesos y grandes zonas de aparcamiento de coches.
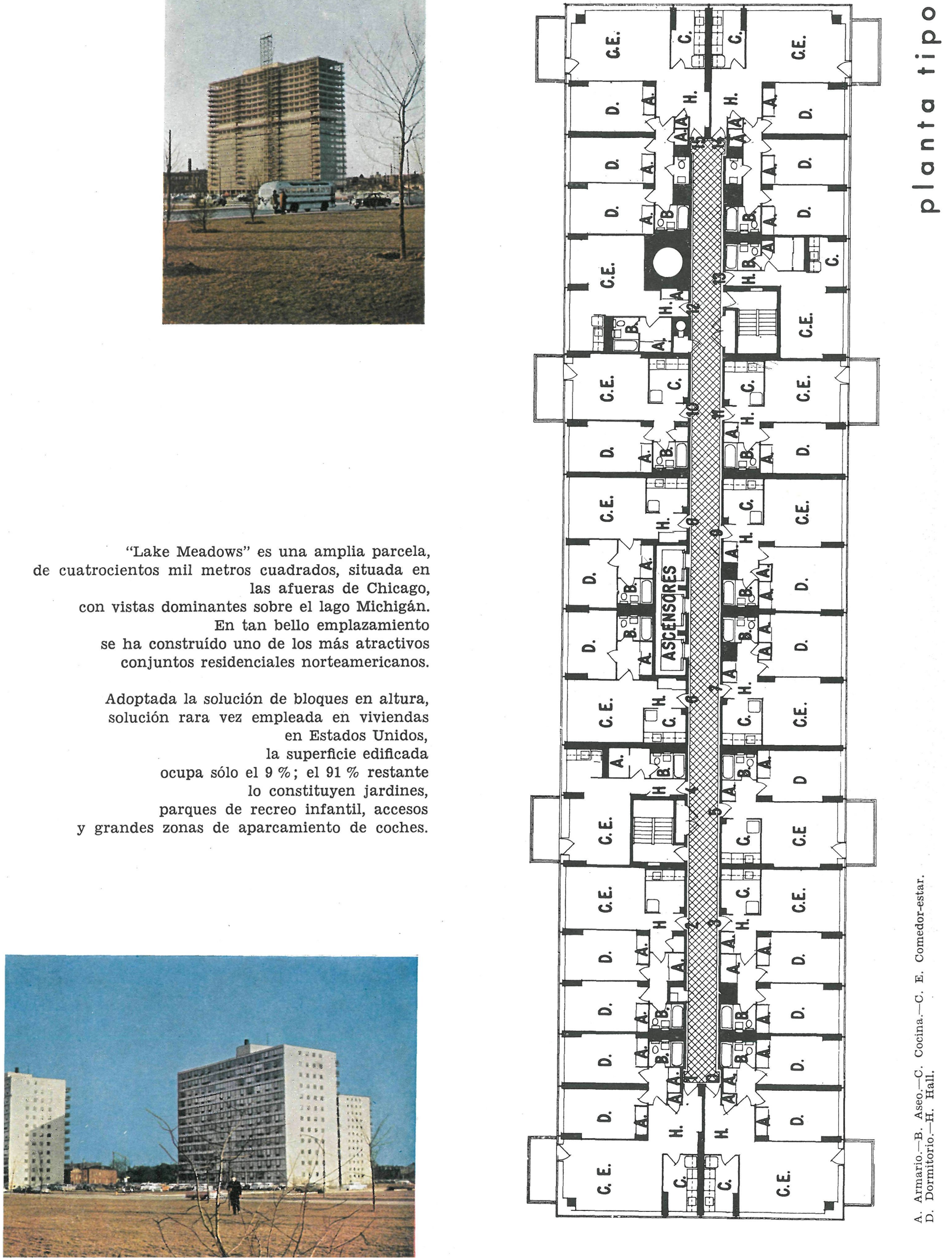


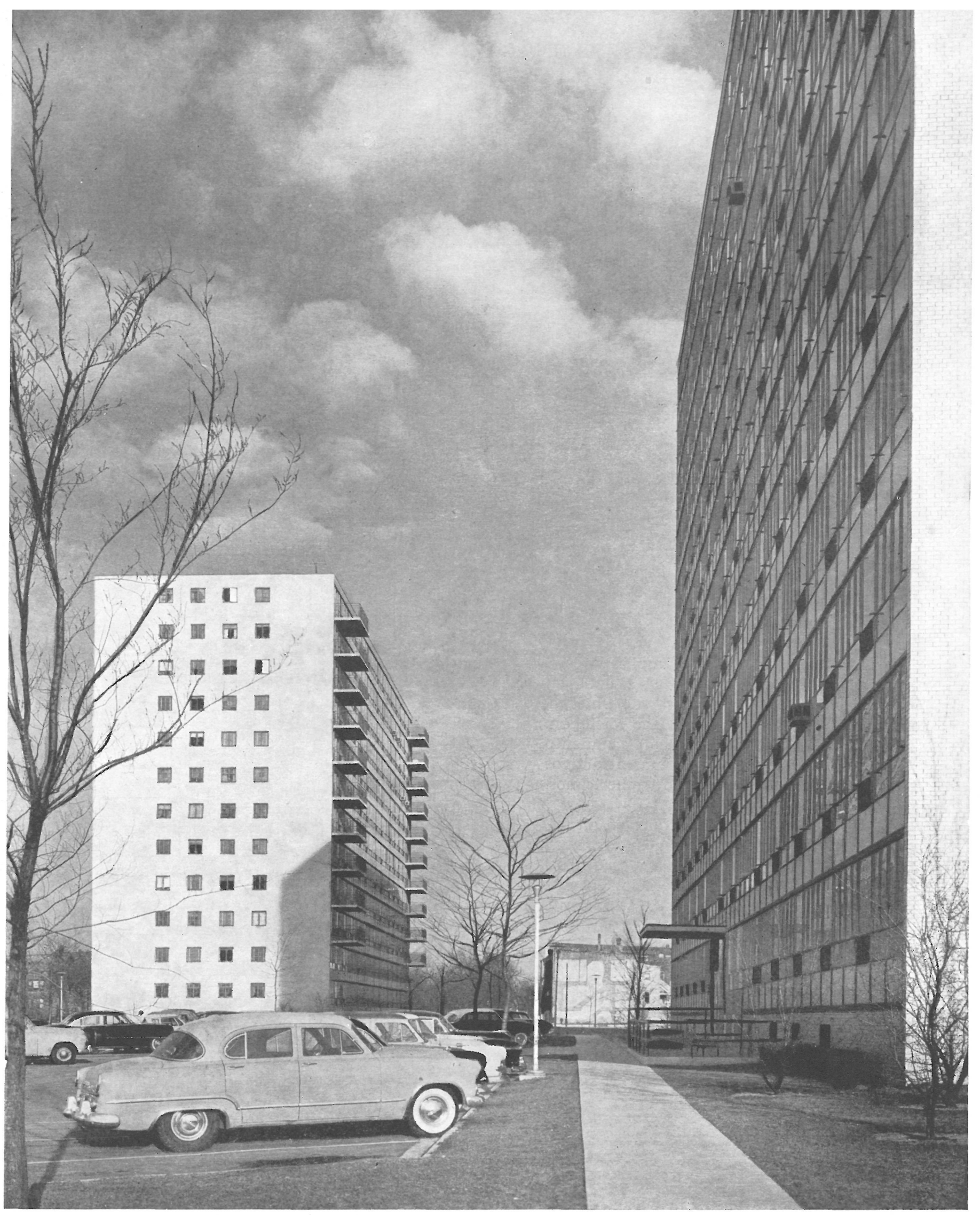

La unidad urbanística creada se compone de:

1. Un conjunto de cinco bloques aislados, de doce plantas cada uno, en los que se distribuyen quinientos noventa y cinco apartamentos con dos, tres o cuatro habitaciones. $\mathrm{Su}$ construcción está acabada y sus viviendas alquiladas. 

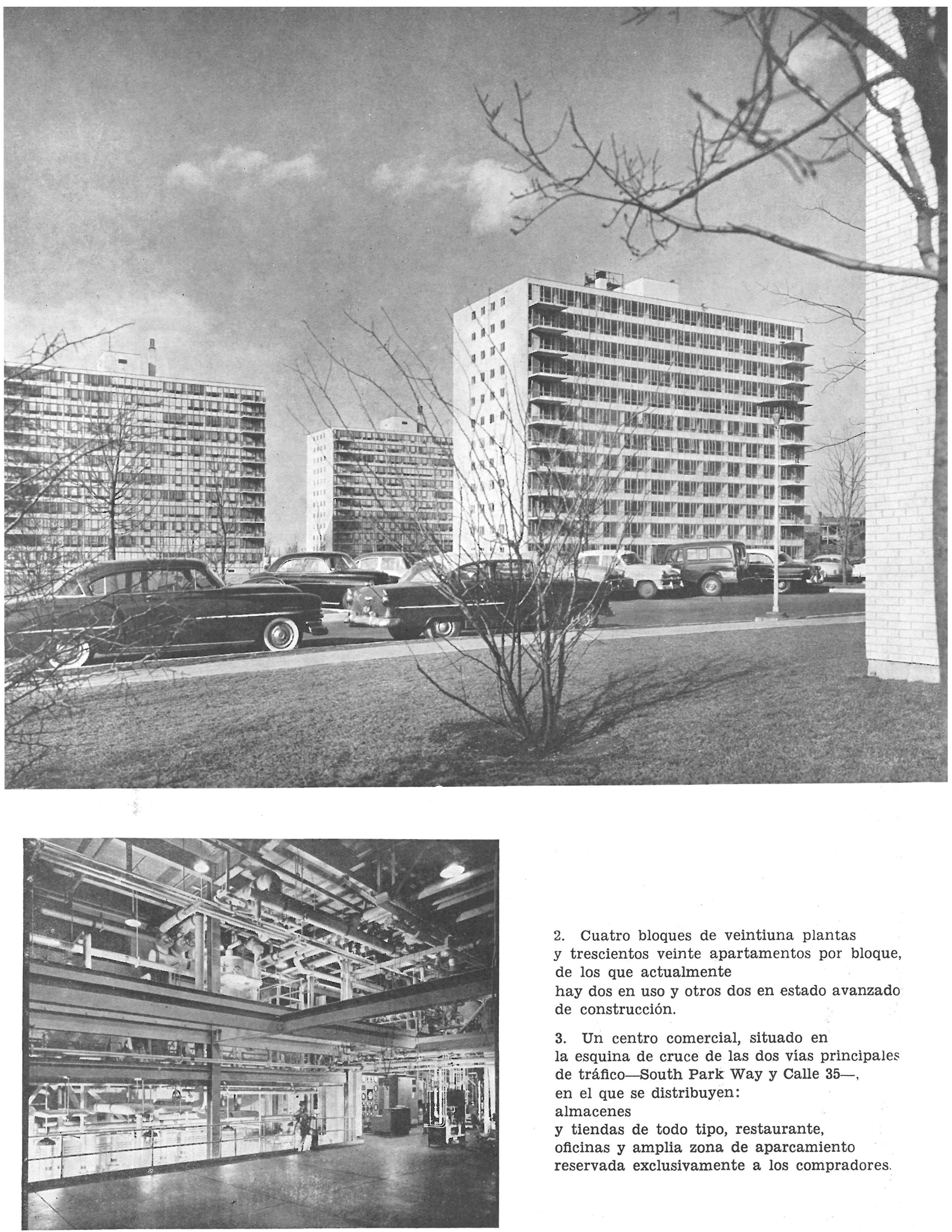

2. Cuatro bloques de veintiuna plantas y trescientos veinte apartamentos por bloque, de los que actualmente

hay dos en uso y otros dos en estado avanzado de construcción.

3. Un centro comercial, situado en la esquina de cruce de las dos vías principales de tráfico-South Park Way y Calle 35-, en el que se distribuyen: almacenes y tiendas de todo tipo, restaurante, oficinas y amplia zona de aparcamiento reservada exclusivamente a los compradores. 


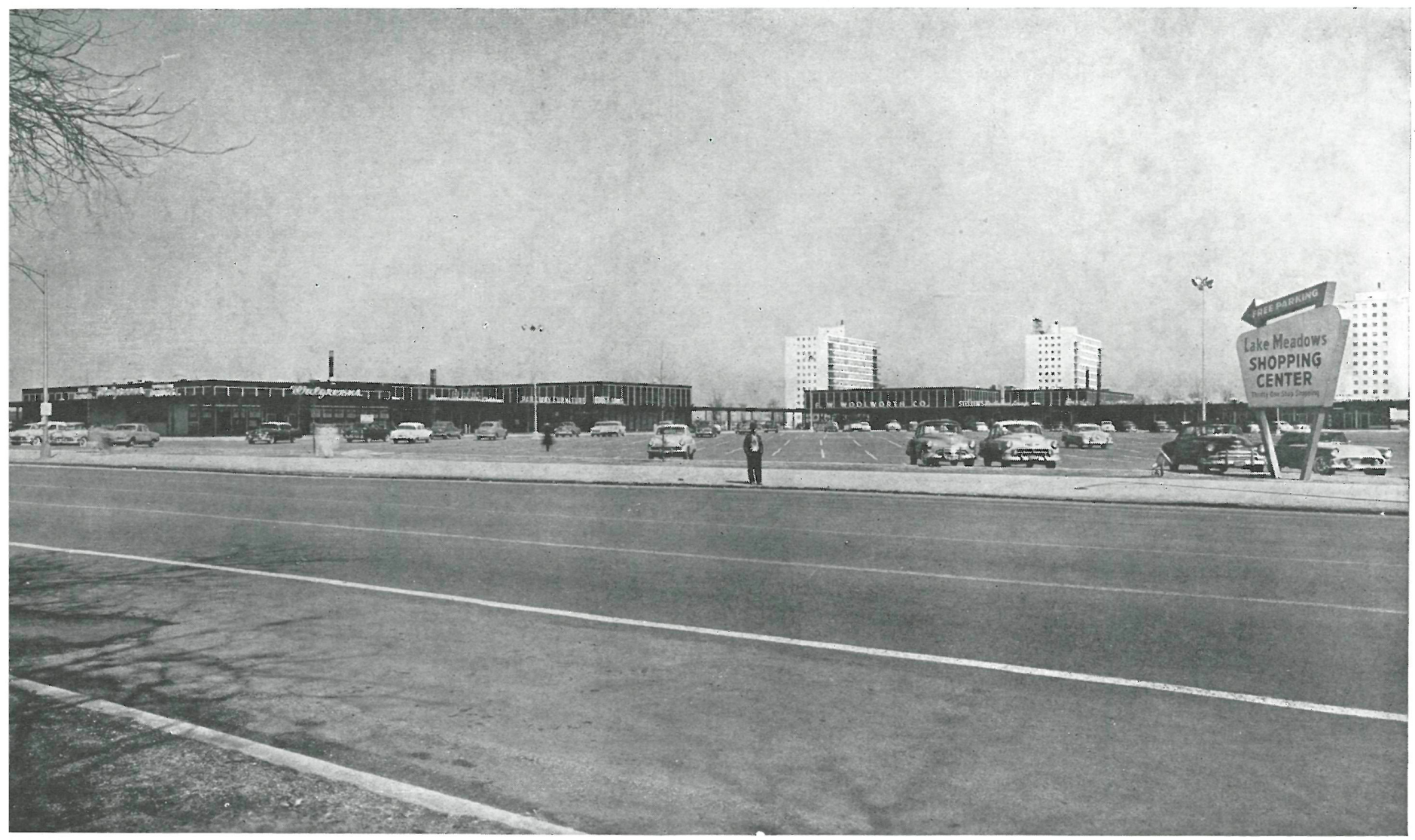

Fotos: HEDRICH - BLESSING Y WILLIAMS \& MEYER CO.

Fotos color: F. CASSINELLO

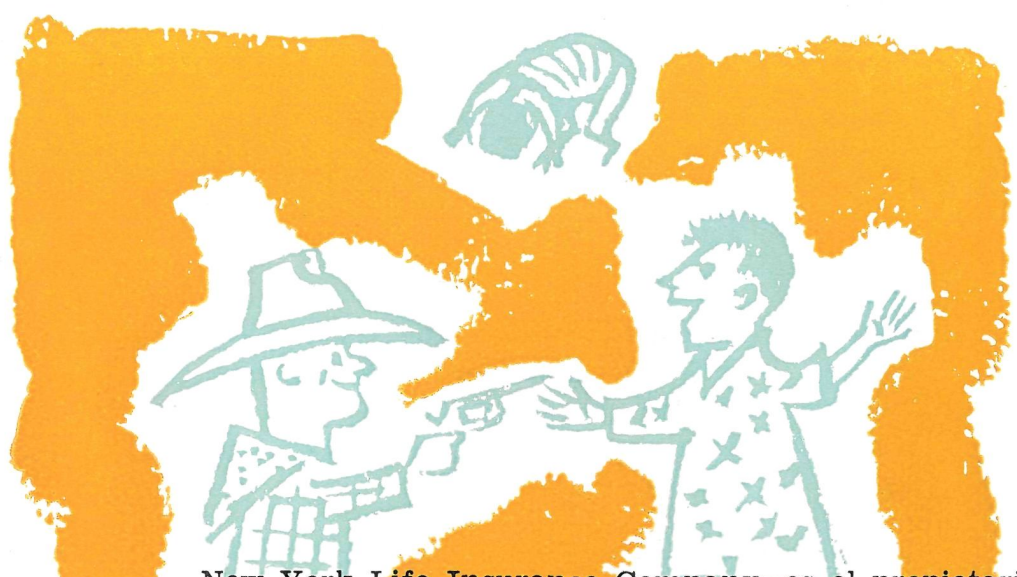

New York Life Insurance Company, es el propietario administrador de este nuevo barrio residencial concebido con gran lujo de espacios libres,

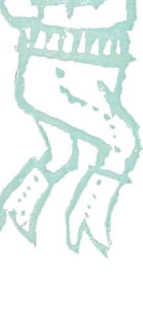
Cristal, acero y ladrillo constituyen el cerramiento de los edificios,
proyectados con la máxima diafanidad exterior, pese el crudo clima de Chicago, gracias a la perfección de sus instalaciones de clima artificial. 